\title{
PERBANDINGAN KUAT TEKAN MORTAR DENGAN MEMANFAATKAN COAL ASH WASTE
}

\author{
Mega Yunanda \\ Dosen Tetap Yayasan Perguruan Tinggi Palembang \\ Prodi Teknik Sipil Fakultas Teknik Universitas Palembang \\ E-mail : megayunanda@gmail.com
}

\begin{abstract}
The utilization of coal ash waste (Fly ash) which is processed into raw material in making mortar, is expected to be useful in daily life, in addition to improve the economy of the community, can also reduce the impact of environmental pollution due to waste from coal ash (Fly ash). And provide information to the public about the effect of addition of coal ash (Fly ash) to the quality of mortar. From the results of this study it can be seen that the strength of mortar pressure without the mixture of coal ash or normal is $109.33 \mathrm{~kg} / \mathrm{cm}$, while for the average compressive strength of mortar mixed with coal ash is $9 \%, 12 \%$, and $15 \%$ respectively, were $156 \mathrm{~kg} / \mathrm{cm} 2$, $125.33 \mathrm{~kg} / \mathrm{cm} 2$, and $110.6 \mathrm{~kg} / \mathrm{cm} 2$. From the results of the study. it can be seen that mortar strength is highest if the variation of coal ash mixture is $9 \%$ of cement amount. While mixing more than $9 \%$ of mortar compressive strength will decrease. Thus the use of coal ash with a content of $9 \%$ is the optimum mixture content in this mixture. If a mixture of coal ash exceeds that level, it will decrease the strength of mortar. This decrease is thought to be due to the less strong bonds between aggregates (mixed materials) on the use of coal ash over $9 \%$
\end{abstract}

Keywords : Coal Ash, Mortar, Pozzolan

\section{PENDAHULUAN}

Mortar merupakan salah satu bahan bangunan yang berfungsi untuk merekatkan pasangan batu bata, batako, plesteran dan sebagainya. Selama ini mortar masih menggunakan semen portland dan kapur sebagai bahan pengikat utama yang harganya cukup mahal. Oleh karena itu diperlukan bahan alternatif pengikat lainnya yang memiliki harga lebih murah dan diperediksikan dapat meningkatkan sifat mekanik mortar. Bahan pengikat alternatif yang digunakan dalam penelitian ini adalah abu batubara (Fly ash).

Mortar adalah campuran semen, pasir dan air yang memiliki persentase yang berbeda. Perbandingan semen, pasir dan air yang sesuai untuk mortar yang memiliki syarat adalah $1: 2,75: 0,484$. sebagai bahan pengikat, mortar harus mempunyai konsistensi/kekentalan standar. Konsistensi mortar ini nantinya akan berguna dalam menentukan kekuatan mortar yang menjadi spesi ataupun plesteran dinding sehingga diharapkan mortar yang menahan gaya tekan akibat beban yang bekerja padanya tidak hancur.

Abu batubara (Fly ash) adalah sisa hasil pembakaran ketel uap (alat untuk memproduksi uap pada jumlah tertentu setiap jamnya dengan tekanan dan suhu tertentu). abu batubara (Fly ash) memiliki unsur yang bermanfaat untuk peningkatan kekuatan mortar, karena mempunyai sifat pozzolan dan mengandung silika yang sangat menonjol. Bila unsur ini dicampur dengan semen akan menghasilkan kekuatan yang lebih tinggi.

Abu batubara (Fly ash) memiliki butiran yang lebih halus daripada butiran semen dan mempunyai sifat hidrolik, maka seharusnya abu batubara (Fly ash) tidak sekedar menambah kekedapan mortar, tetapi juga dapat menambah kekuatannya. Pemikiran ini sangat beralasan, karena secara mekanik abu batubara (Fly ash) ini akan mengisi ruang kosong (rongga) diantara butiran - butiran semen. 
Pada penelitian ini pemanfaatan abu batubara (Fly ash) tidak hanya untuk kepentingan bahan bangunan, tetapi juga merupakan suatu usaha untuk membantu menanggulangi masalah lingkungan, abu batubara (Fly ash) yang sebagian besar unsur utamanya adalah silika dapat mengakibatkan pencemaran lingkungan yang berbahaya bagi kesehatan.

\section{TINJAUAN PUSTAKA 2.1 Mortar}

Mortar adalah campuran semen, pasir dan air yang memiliki persentase yang berbeda. Perbandingan semen, pasir dan air yang sesuai untuk mortar yang memenuhi syarat adalah $1: 2,75: 0,485$. Sebagai bahan pengikat, mortar harus mempunyai konsentrasi/kekentalan standar. Konsentrasi mortar ini nantinya akan berguna dalam menentukan kekuatan mortar yang menjadi spesi ataupun plesteran dinding sehingga diharapkan mortar yang menahan gaya tekan akibat beban yeng bekerja padanya tidak hancur (Teknologi Beton, 2008).

Mortar dapat digunakan dalam bentuk pasta kubus beton (struktur) maupun non struktur, misalnya pada pekerjaan pasangan dinding bata atau batako, pekerjaan plesteran dinding, pekerjaan pasangan keramik dinding, pekerjaan perataan dasar lantai sampai pada pekerjaan pasangan keramik lantai.

Mortar dan beton dibuat dari semen dan agregatnya yang dicampur dengan air. Yang perlu diketahui dari bahan bangunan adalah sifat kerapatan (densitas), porositas dan kekuatan tekan. Dalam hubungan dengan panas maka mortar juga perlu diketahui sifat-sifatnya, misalnya sebuah dinding yang terbuat dari beton mempunyai konduktifitas yang berbeda dengan bahan bangunan erat sekali hubungannya dengan penggunaan bahan bangunan.

\subsection{Spesifikasi Mortar}

\subsubsection{Spesifikasi Proporsi dan Sifat Mortar}

Berdasarkan SNI 03-6882-2002, proporsi mortar di spesifikasikan dalam 4 tipe menurut kekuatan mortar dan ketentuan spesifikasi proporsi bahan yang terdiri dari bahan bersifat semen, agregat, dan air yang digunakan.

Tipe - tipe mortar adalah sebagai berikut :

a) Mortar tipe $\mathbf{M}$

Mortar tipe $\mathrm{M}$ adalah mortar yang mempunyai kekuatan $17,2 \mathrm{MPa}$ menurut Tabel 2.2, yang dibuat dengan menggunakan semen pasangan tipe $\mathrm{N}$ atau kapur semen dengan menambahkan semen portland dan kapur padam dengan komposisi menurut Tabel 2.1.

b) Mortar tipe $\mathbf{S}$

Mortar tipe $\mathrm{S}$ adalah mortar yang mempunyai kekuatan 12,5 $\mathrm{MPa}$ menurut Tabel 2.2, yang dibuat dengan menggunakan semen pasangan tipe $\mathrm{S}$ atau kapur semen dengan menambahkan semen portland dan kapur padam dengan komposisi menurut Tabel 2.1.

c) Mortar tipe $\mathbf{N}$

Mortar tipe $\mathrm{N}$ adalah mortar yang mempunyai kekuatan 5,2 $\mathrm{MPa}$ menurut Tabel 2.2, yang dibuat dengan menggunakan semen pasangan tipe $\mathrm{N}$ atau kapur semen dengan menambahkan semen portland dan kapur padam dengan komposisi menurut Tabel 2.1.

d) Mortar tipe $\mathbf{O}$

Mortar tipe $\mathrm{O}$ adalah mortar yang mempunyai kekuatan 2,4 $\mathrm{MPa}$ menurut Tabel 2.2, yang dibuat dengan menggunakan semen pasangan tipe $\mathrm{N}$ atau kapur semen dengan menambahkan semen portland dan kapur padam dengan komposisi menurut Tabel 2.1.
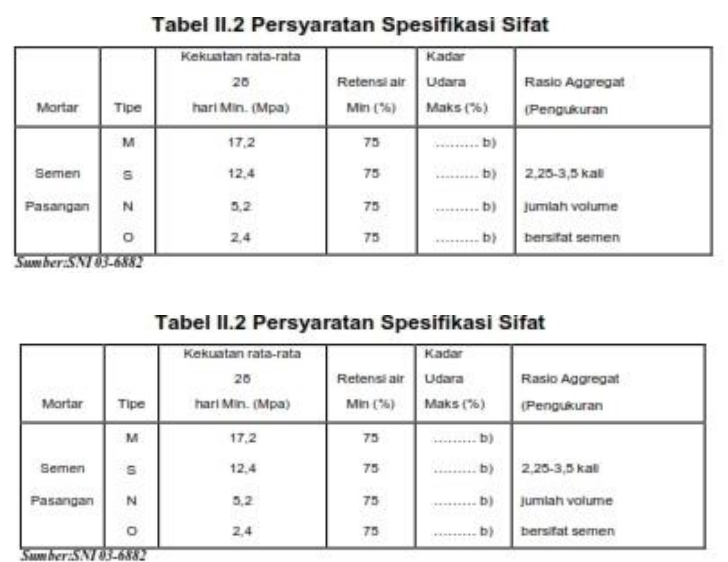

Keterangan:

a. Hanya untuk mortar yang dipersiapkan di laboratorium. 
b.Bila terdapat tulangan struktur dalam mortar semen pasangan maka kadar udara maksimum harus $18 \%$.

Spesifikasi sifat mortar harus memenuhi ketentuan persyaratan bahan dan pengujian terhadap mortar yang telah disiapkan dilaboratorium, dimana bahan tersebut terdiri dari suatu campuran bahan pengikat bersifat semen, agregat dan air yang telah memenuhi persyaratan mortar sesuai metode pengujian yang telah dikeluarkan oleh SNI 03-6882-2002

\subsubsection{Metode Pengujian}

\section{a) Proporsi campuran bahan untuk benda uji \\ Mortar yang dibuat}

dilaboratorium yang digunakan untuk menentukan sifat - sifat menurut spesifikasi ini harus berisi bahan bahan konstruksi dalam susunan campuran yang telah ditetapkan dalam spesifikasi proyek (SNI 03-6882-2002).

\section{b) Pencampuran Mortar}

Semua bahan bersifat semen dan agregat harus dicampur dengan sejumlah air secukupnya selama $3-5$ menit dengan menggunakan alat pengaduk mekanis untuk menghasilkan mortar yang mudah dikerjakan. Pencampuran mortar dengan tangan diperbolehkan bila ada ijin dari pihak yang menentukan persyaratan dengan memberikan prosedur cara pencampuran yang dimaksud (SNI 036882-2002).

\section{c) Pemeliharaan Kelecekan}

Mortar yang telah mengeras harus diaduk kembali dengan tangan untuk mempertahankan kelecekannya, dan mortar yang telah mencapai lebih dari 2,5 jam sejak dicampur tidak boleh dipakai lagi (SNI 03-6882-2002).

\subsubsection{Kuat Tekan Mortar}

Untuk mengetahui perbandingan kuat tekan mortar dengan varian berbeda, perhitungan kuat tekan mortar menggunakan rumus :

$$
\mathrm{f}^{\prime} \mathrm{c}={ }^{\mathrm{P}} \mathrm{A}
$$

f'c = kuat tekan mortar, dalam MPa

$\mathrm{P} \quad=$ beban maksimum total, dalam $\mathrm{N}$

A = luas dari permukaan yang dibebani, dalam mm2

Faktor-faktor yang sangat mempengaruhi kuat tekan mortar diantaranya adalah faktor air semen, jumlah semen, umur mortar, dan sifat agregat.

\section{a) Faktor air semen (f a s)}

Faktor air semen adalah angka perbandingan antara berat air dan berat semen dalam campuran mortar atau beton. Secara umum. diketahui bahwa semakin tinggi nilai f.a.s., semakin rendah mutu kekuatan beton. Namun demikian, nilai f.a.s. yang semakin rendah tidak selalu berarti bahwa kekuatan beton semakin tinggi. Nilai f.a.s. yang rendah akan menyebabkan kesulitan dalam pengerjaan, yaitu kesulitan dalam pelaksanaan pemadatan yang pada akhirnya akan menyebabkan mutu beton menurun. Umumnya nilai f.a.s. minimum yang diberikan sekitar 0,4 dan maksimum 0,65 (Tri Mulyono, 2004).

b) Jumlah Semen

Pada mortar dengan f.a.s sama, mortar dengan kandungan semen lebih banyak belum tentu mempunyai kekuatan lebih tinggi. Hal ini disebabkan karena jumlah air yang banyak, demikian pula pastanya, menyebabkan kandungan pori lebih banyak daripada mortar dengan kandungan semen yang lebih sedikit. Kandungan pori inilah yang mengurangi kekuatan mortar. Jumlah semen dalam mortar mempunyai nilai optimum tertentu yang memberikan kuat tekan tinggi.

c) Umur Mortar

Kekuatan mortar akan meningkat seiring dengan bertambahnya umur dimana pada umur 28 hari mortar akan memperoleh kekuatan yang diinginkan.

d) Sifat Agregat

Sifat agregat yang berpengaruh terhadap kekuatan ialah bentuk, kekasaran permukaan, kekerasan dan ukuran maksimum butir agregat. Bentuk dari agregat akan berpengaruh terhadap interlocking antar agregat. 


\subsection{Material}

\subsubsection{Semen}

Material semen adalah material yang mempunyai sifat-sifat adhesif dan kohesif yang diperlukan untuk mengikat agregat-agregat menjadi suatu massa yang padat yang mempunyai kekuatan yang cukup

Faktor semen sangatlah mempengaruhi karakteristik campuran mortar. Kandungan seman hidraulik yang tinggi akan memberikan banyak keutungan, antara lain dapat membuat campuran mortar menjadi lebih kuat, lebih padat, lebih tahan air, lebih cepat mengeras dan juga memberikan rekatan yang lebih baik. Kerugiannya adalah dengan cepat campuran mengeras, maka dapat menyebabkan susut kering yang lebih tinggi pula. Mortar dengan kandungan hidraulik rendah akan lebih lemah dan mudah dalam pergerakan.

\subsubsection{Semen Portland}

Menurut SNI 03-2847-2002, portland cement merupakan bahan perekat dalam campuran beton hasil penghalusan klinker yang senyawa utamanya terdiri dari material calcareous seperti limestone atau kapur dan material argillaceous, seperti besi oksida, serta silica dan alumina yang berupa lempung. proses pencampuran dilakukan di dalam tempat pembakaran dengan temperature sekitar $1300-1450^{\circ} \mathrm{C}$ sampai membentuk klinker. setelah didinginkan ditambah dengan sejumlah material gypsum $(\mathrm{CaSO} 4.2 \mathrm{H} 2 \mathrm{O})$ dan bahan inert pada saat penggilingan terakhirnya. pemberian gypsum 3 - 5\% bertujuan untuk mengendalikan waktu ikat semen agar tidak berlangsung lama.

\subsubsection{Pozzolan}

Abu ampas tebu termasuk bahan pozzolan. Pozzolan adalah bahan yang mengandung senyawa silica dan alumina, yang tidak mempunyai sifat semen, akan tetapi dalam bentuk halusnya dan dengan adanya air dapat menjadi suatu massa padat yang tidak larut dalam air.

Pozzolan dapat ditambahkan pada campuran adukan beton dan mortar (sampai pada batas tertentu dapat menggantikan semen), untuk memperbaiki kelecekan, membuat beton menjadi lebih kedap air (mengurangi permeabilitas) dan yang bersifat agresif.

\subsection{Agregat}

Dalam struktur beton biasanya agregat menempati kurang lebih 70 sampai $75 \%$ dari volume massa yang mengeras. Sisanya terdiri dari adukan semen yang telah mengeras, air yang belum bereaksi (yaitu, air yang tidak ikut dalam proses hidrasi dari semen) dan ronggarongga udara. Air yang belum bereaksi dan rongga-rongga udara kenyataannya tidak memberikan sumbangan kekeuatan terhadap beton. Pada umumnya, semakin padat agregatagregat tersebut tersusun, semakin kuat pula beton yang dihasilkannya, daya tahannya terhadap cuaca dan nilai ekonomis dari beton tersebut.

Sifat agregat bukan hanya mempengaruhi sifat beton, akan tetapi juga mempengaruhi ketahanan (durability, daya tahan terhadap kemunduran mutu akibat siklus dari pembekuan-pencairan). Oleh karena agregat lebih murah dari semen, maka adalah logis untuk menggunakannya dengan persentase yang setinggi mungkin. Umumnya untuk kekuatan yang maksimum, ketahanan dan ekonomis, agregat halus disemen sepadat mungkin.

Agregat yang digunakan campuran beton dapat berupa agregat alam atau ageregat buatan (artificial aggregates). Secara umum, agregat dapat dibedakan berdasarkan ukurannya, yaitu, agregat kasar dan agregat halus. Batasan antara agregat halus dan kasar berbeda antara disiplin ilmu yang satu dengan yang lain. Meskipun demikian, dapat diberikan batasan ukuran antara agregat haus dengan agregat kasar yaitu $4.80 \mathrm{~mm}$ (British Standar) atau $4.75 \mathrm{~mm}$ (Standar ASTM). Agregat kasar adalah batuan yang ukuran butirannya lebih besar dari $4.80 \mathrm{~mm}(4.75 \mathrm{~mm})$ dan agregat haus adalah batuan yang lebih kecil dari 4.80 $\mathrm{mm}(4.75 \mathrm{~mm})$. agregat dengan ukuran lebh besar dari $4.80 \mathrm{~mm}$ dibagi menjadi dua : yang berdiameter antara $4.80-40 \mathrm{~mm}$ disebut kerikil beton dan yang lebih dari $40 \mathrm{~mm}$ disebut kerikil kasar.

Agregat halus merupakan pengisi yang berupa pasir. Agregat halus yang baik harus bebas bahan organik, lempung, partikel yang lebih kecil, atau bahan-bahan lain yang dapat merusak campuran. Variasi ukuran dalam 
suatu campuran barus mempunyai gradasi yang baik.

Kekuatan mortar akan bertambah jika kandungan pori dalam mortar semakin kecil. Terjadi hubungan langsung antara kekuatan dengan kandungan pori dalam agregat. Semakin tinggi angka pori dalam agregat berarti semakin tinggi angka pori dalam mortar yang pada akhirnya akan menyebabkan turunnya kekuatan mortar.

Pasir merupakan agregat alami yang berasal dari letusan gunung berapi, sungai, dalam tanah dan pantai oleh karena itu pasir dapat digolongkan dalam tiga macam yaitu pasir galian, pasir laut dan pasir sungai.

\subsection{Air}

Air diperlukan pada pembuatan mortar untuk memicu proses kimiawi semen, membasahi agregat dan memberi kemudahan dalam pekerjaan mortar. Air yang dapat diminum umumnya dapat digunakan sabagai campuran mortar. Air yang mengandung senyawa-senyawa yang berbahaya, yang tercemar garam, minyak, gula, atau bahan kimia lainnya, bila dipakai dalam campuran mortar akan menurunkan kualitas mortar, bahkan dapat mengubah sifat mortar yang dihasilkan.

Karena pasta semen merupakan hasil reaksi kimia antara semen dengan air, maka bukan perbandingan jumlah air terhadap total berat campuran yang penting, tetapi justru perbandingan air dengan semen atau yang sering disebut sebgai Faktor Air Semen (water cement ratio). Air yang berlebihan akan menyebabkan banyaknya gelembung air setelah proses hidrasi selesai, sedangkan air yang terlalu sedikit akan menyebabkan proses hidrasi tidak tercapai seluruhnya, sehingga akan mempengaruhi kekuatan mortar.

Tabel 2.3. Batas dan Izin Air Untuk Campuran mortar

\begin{tabular}{|c|c|}
\hline & Batas yang diizinkan \\
\hline $\mathrm{Ph}$ & $4,5-8,5$ \\
\hline Bahan padat & $2000 \mathrm{ppm}$ \\
\hline Bahan terlarut & $2000 \mathrm{ppm}$ \\
\hline Bahan organic & $2000 \mathrm{ppm}$ \\
\hline Minyak & $2 \%$ berat semen \\
\hline Sulfur $\left(\mathrm{SO}_{3}\right)$ & $10000 \mathrm{ppm}$ \\
\hline Chlor $(\mathrm{C} 1)$ & $10000 \mathrm{ppm}$ \\
\hline
\end{tabular}

Air memiliki beberapa pengaruh terhadap kekuatan mortar antara lain :

1.Air merupakan media pencampur pada pembuatan pasta.

2.Kekuatan dari pasta pengerasan semen ditentukan oleh perbandingan berat antara air dan faktor semen.

3.Kandungan air yang tinggi menghalangi proses pengikatan dan kandungan air yang rendah reaksinya tidak selesai

Air sangat diperlukan pada pembuatan mortar agar terjadi reaksi kimiawi dengan semen. pada umumnya air minum dapat dipakai untuk campuran beton. Air yang mengandung senyawa - senyawa berbahaya, yang tercemar garam, minyak gula atau bahan - bahan kimia lain, bila dipakai untuk campuran mortar akan dapat menurunkan kekuatannya dan dapat juga mengubah sifat sifat semen.

Karena karakteristik pasta semen merupakan hasil reaksi kimiawi antara semen dan air, maka bukan perbandingan jumlah air terhadap total material yang menentukan , melainkan hanya perbandingan antara air dan semen pada campuran yang menentukan. air yang berlebihan akan menyebabkan banyaknya gelembung air setelah proses hidrasi selesai. sedangkan air yang terlalu sedikit akan menyebabkan proses hidrasi tidak seluruhnya selesai. Sebagai akibatnya mortar yang dihasilkan akan kurang kekuatannya.

\section{METODE PENELITIAN}

\subsection{Bagan Alir Penelitian}

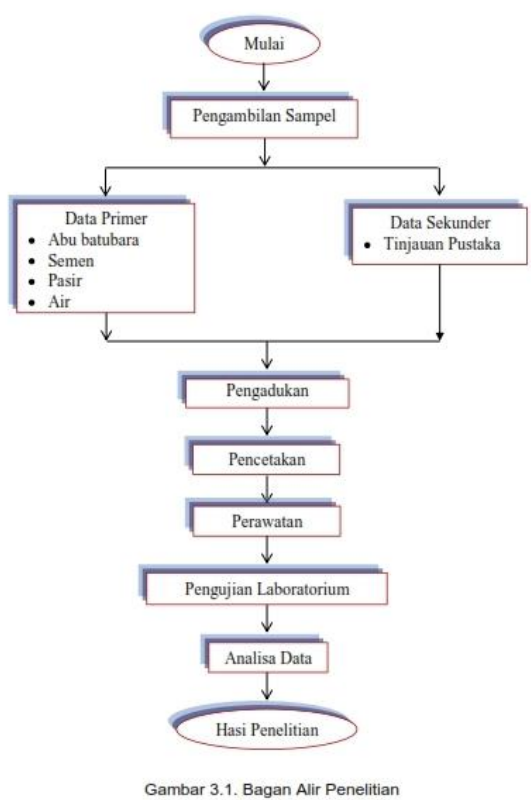




\subsection{Lokasi Penelitian}

Penelitian ini dilakukan di Laboratorium Struktur dan Bahan Program Studi Teknik Sipil Fakultas Teknik Universitas Palembang dengan waktu penelitian selama dua bulan.

\subsection{Jenis Penelitian dan Sumber Data}

Penelitian yang dilakukan adalah uji eksperimental, di mana kondisi dibuat dan diatur oleh peneliti dengan mengacu pada peraturan SNI (Standar Nasional Indonesia) serta literatur yang berkaitan

\subsection{Alat dan Bahan Penelitian}

1. Timbangan dengan ketelitian 0,1 gram

2. Gelas ukur $1000 \mathrm{ml}$ Gelas ukur, digunakan untuk mengukur banyaknya air yang digunakan.

3. Piknometer.

4. Kerucut terpancung

5. Batang perojok

6. Pan aluminium

7. Pelat kaca

8. Cawan

9. Oven yang dilengkapi pengatur suhu.

10. Density spoon

11. Timbangan

12. Tabung silinder

13. Jangka sorong, digunakan untuk mengukur semua dimensi benda uji.

14. Kuas

15. Ember plastic

16. Cetakan kubus dengan ukuran (5 x 5 x 5) $\mathrm{cm}$

17. Sendok semen

18. Universal Testing Machine (Tokyo Testing Machine Inc.) kapasitas 1000 $\mathrm{kN}$

19. Ayakan, Lolos saringan No. 200 (komposisi agregat halus sesuai dengan standar)

20. Kain basah.

\subsection{Bahan}

Bahan yang digunakan dalam penelitian ini adalah :

1. Semen Portland Tipe I

2. Agregat halus adalah pasir

3. Air PDAM

4. Abu batubara (Fly ash)

\subsection{Prosedur Pembuatan Bahan Uji} Mortar

1. Pencampuran

Bahan-bahan seperti semen dan pasir ditimbang dengan perbandingan $1: 2,75$ dan Abu batubara (Fly ash) sebanyak 0\%, $9 \%, 12 \%$, dan $15 \%$ dari berat semen.

2. Pengadonan

Setelah semua bahan dicampur maka bahan tersebut diberi air pada bagian tengah adonan serta dibiarkan selama 60 detik agar campuran saling mengikat lalu campuran tersebut diaduk sampai campuran benar-benar homogen.

3. Pencetakan

Setelah pengadonan selesai dilakukan pencetakan dengan memasukkan pasta mortar kedalam cetakan kubus yang telah diolesi Vaseline terlebih dahulu dengan cara :

- Di masukkan pasta setinggi 1/3 tinggi cetakan, kemudian campuran dirojok paling sedikit 25 kali untuk menjamin kepadatan susunan campuran.

- Di masukkan kembali 1/3 pasta mortar ke dalam cetakan kemudian dirojok kembali.

- Di masukkan kembali pasta mortar kedalam cetakan sampai penuh kemudian dirojok kembali.

- Diratakan permukaan cetakan lalu ditutup dengan kain basah selama \pm 24 jam .

\subsection{Perencanaan Campuran dan Prosedur Uji Kualitas Mortar \\ 3.7.1 Perencanaan Campuran Mortar}

Campuran mortar berpedoman pada Standard ASTM C109-93, yaitu:

- Cetakan kubus 5 x 5 x 5 cm

- Sampel dapat dibuat dengan perincian bahan adalah

Tabel 3.1. Bahan sampel

\begin{tabular}{|c|c|}
\hline & 3 sampel \\
\hline Semen & 250 gram \\
\hline Pasir & 687,5 gram \\
\hline Air & $121 \mathrm{ml}$ \\
\hline
\end{tabular}

\subsubsection{Prosedur Pengujian Kekuatan Tekanan Mortar}

Pengujian kuat tekanan mortar dilakukan untuk mengetahui kuat tekan hancur dari benda uji tersebut. Benda uji yng dipakai adalah kubus dengan ukuran sisinya (5 x 5 x 5 ) 
$\mathrm{cm}$. pengujian kuat tekanan mortar dilakukan saat mortar berumur 7, 14, 21 dan 28 hari. Jumlah mortar yang di uji yaitu terdiri dari 3 buah sampel untuk masingmasing campuran.

Prosedur kerja untuk pengujian kuat tekan pada benda uji mortar, antara lain :

1. Dikeluarkan benda uji setelah mencapai umur yang direncanakan dari bak perendaman lalu dikeringkan dengan lap dan dibiarkan selama 24 jam.

2. Benda uji diletakkan pada mesin penekan.

3. Diberikan beban tekan secara perlahanlahan pada benda uji dengan cara mengoperasikan tuas pompa sehingga benda uji runtuh dan hancur.

4. Pada saat jarum penunjuk skala beban tidak lagi bergerak atau bertambah maka skala yang ditunjukkan oleh jarum tersebut dicatat sebagai beban maksimum yang dapat dipikul oleh benda uji tersebut.

5. Prosedur ini diulang untuk sampel benda uji kuat tekan yang lain.

Kuat tekan dapat diperoleh dengan rumus, sebagai berikut :

$f c^{I}=\frac{F}{A}$

$\mathrm{FcI}=$ Kuat tekan benda uji $(\mathrm{kg} / \mathrm{cm} 2)$

$\mathrm{F}=$ Beban tekan maksimum $(\mathrm{kg})$

$\mathrm{A}=$ Luas bidang permukaan $(\mathrm{cm} 2)$

\section{IV.HASIL DAN PEMBAHASAN}

\subsection{Karakteristik Agregat}

Material yang digunakan dalam penelitian ini yaitu agregat halus (pasir) dan semen portland komposit. Pengujian agregat ini mengacu pada SNI (Standar Nasional Indonesia). Pengujian ini dilakukan di Laboratorium Struktur dan Bahan Program Studi Teknik Sipil Fakultas Teknik Universitas Palembang. Hasil pemeriksaan agregat halus (pasir) yang dilakukan sebelum pembuatan benda uji dapat dilihat pada tabel berikut,
Tabel. 4.1. Hasil Pengujian Agregat Halus

\begin{tabular}{|c|c|c|c|c|}
\hline No. & Jenis pengujian & $\begin{array}{c}\text { Hasil } \\
\text { Pengujian }\end{array}$ & Spesifikasi & SNI \\
\hline 1. & Berat Jenis : & & \multirow{4}{*}{$1,60-3,20$} & \multirow{4}{*}{$\begin{array}{c}\text { SNI } 03-1968 \\
1990\end{array}$} \\
\hline & Bj. Kering Oven & 2,38 & & \\
\hline & Bj. Kering permukaan & 2,53 & & \\
\hline & Bj. Semu & 2,78 & & \\
\hline 2. & Modulus kehalusan & $\begin{array}{c}2,4 \\
4\end{array}$ & $2,30-3,10 \%$ & $\begin{array}{c}\text { SNI 1970: } \\
2008\end{array}$ \\
\hline
\end{tabular}

\subsection{Rancang Campuran Mortar}

Komposisi campuran mortar untuk 3 benda uji dibuat dengan standar ASTM C10993 yang dapat dilihat pada tabel 4.1. perbandingan bahan-bahan kering yang digunakan adalah 1 bagian berat semen, 2,75 bagian berat pasir dan faktor air semen adalah 0,484 untuk semua jenis semen portland.

Tabel 4.1. Komposisi campuran Mortar Standar (MS) dan Mortar yang dicampur dengan Limbah abu batubara (MA).

\begin{tabular}{|l|c|c|c|c|}
\hline \multicolumn{1}{|c|}{ Uraian } & MS $\%$ & MA-9 $\%$ & MA-12\% & MA-15\% \\
\hline $\begin{array}{l}\text { Limbah Abu } \\
\text { Batubara (gram) }\end{array}$ & 0 & 22,5 & 30 & 37,5 \\
\hline Semen (gram) & 250 & 250 & 250 & 250 \\
\hline Pasir (gram) & 687,5 & 687,5 & 687,5 & 687,5 \\
\hline Air (ml) & 121 & 121 & 121 & 121 \\
\hline
\end{tabular}

Keterangan :

MS $=$ Mortar Standar

MA- $9 \%=$ Mortar yang dicampur abu batubara $9 \%$ terhadap berat semen

MA- $12 \%=$ Mortar yang dicampur abu batubara $12 \%$ terhadap berat semen

MA-15\% =Mortar yang dicampur abu batubara $15 \%$ terhadap berat semen

\subsection{Pengujian Kuat Tekan Mortar}

Pengujian kuat tekan mortar dilakukan dengan menggunakan alat Mesin Compressor (Compressor Mechine). Kuat tekan mortar dapat diperoleh dengan menggunakan rumus :

$$
f_{c}^{\prime}=\frac{F}{A}
$$

Tabel 4.6. Kuat Tekan Rata-rata Mortar

\begin{tabular}{|l|c|c|c|c|}
\hline \multirow{2}{*}{ Benda Uji } & \multicolumn{4}{|c|}{ Kuat Tekan $\left(\mathrm{kg} / \mathrm{cm}^{2}\right)$ pada umur } \\
\cline { 2 - 5 } & 7 hari & 14 hari & 21 hari & 28 hari \\
\hline MS & 37,33 & 64 & 78,67 & 109,33 \\
\hline MA-9\% & 56,00 & 84,00 & 126,67 & 156,00 \\
\hline MA-12\% & 50,67 & 74,67 & 94,67 & 125,33 \\
\hline MA-15\% & 41,33 & 66,67 & 81,33 & 110,67 \\
\hline
\end{tabular}




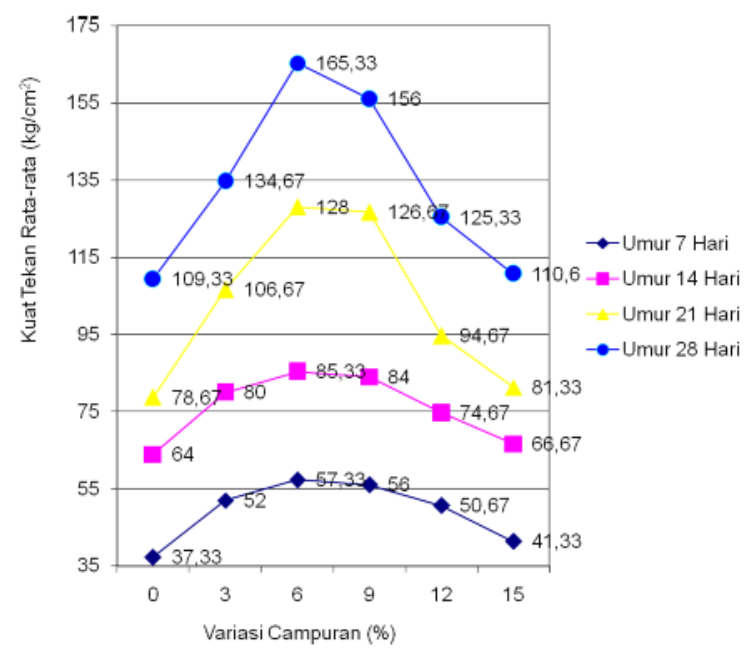

Gambar 4.5. Pengaruh variasi campuran terhadap Kuat Tekan Mortar

Dari gambar 4.5. dapat dilihat bahwa kuat tekanan mortar tanpa campuran abu batubara atau normal adalah sebesar $109,33 \mathrm{~kg} / \mathrm{cm}$, sedangkan untuk kuat tekan rata-rata mortar yang dicampur dengan abu batubara adalah sebesar $9 \%, 12 \%$, dan 15 $\%$ berturut-turut adalah $156 \mathrm{~kg} / \mathrm{cm} 2$, $125,33 \mathrm{~kg} / \mathrm{cm} 2$, dan $110,6 \mathrm{~kg} / \mathrm{cm} 2$.

Dari gambar 4.5. dapat diketahui bahwa kekuatan mortar paling tertinggi jika variasi campuran abu batubara 9\% dari jumlah semen. Sedangkan pencampuran lebih dari 9\% kuat tekan mortar akan menurun. Dengan demikian penggunaan abu batubara dengan kadar 9\% merupakan kadar campuran optimum pada campuran ini. Jika digunakan campuran abu batubara melebihi kadar tersebut maka akan menurunkan kekuatan mortar. Penurunan ini diperkirakan disebabkan oleh ikatan antara agregat (bahan campuran) yang kurang kuat pada penggunaan abu batubara diatas $9 \%$

\section{KESIMPULAN DAN SARAN 5.1 Kesimpulan}

Dari hasil penelitian dan pengujian mortar dengan variasi campuran abu ampas tebu dapat disimpulkan bahwa :

1. Nilai kuat tekan mortar dengan pencampuran abu ampas tebu 3\% dan $6 \%$ akan meningkat dari mortar normal. Sedangkan mortar dengan pencampuran abu ampas tebu 9\%, $12 \%$ dan 15\% cendrung menurun dari mortar dengan pencampuran abu ampas tebu 6\%. Dengan demikian penggunaan abu ampas tebu dengan kadar $6 \%$ yaitu $165,33 \mathrm{~kg} / \mathrm{cm} 2$ merupakan kadar campuran optimum pada campuran ini.

2. Nilai kuat tekan mortar standar dan penambahan abu ampas tebu pada umur 14, 21 dan 28 hari dapat digunakan sebagai bahan bangunan karena sudah memenuhi standar kuat tekan. Kecuali pada umur 14 hari benda uji mortar standar dan mortar yang dicampur abu ampas tebu 15\% tidak memenuhi standar kuat tekan.

3. Nilai penyerapan air dengan menggunakan abu ampas tebu akan semakin menurun seiring dengan bertambahnya variasi campuran abu ampas tebu.

4. Nilai porositas dengan menggunakan abu ampas tebu akan semakin menurun seiring dengan bertambahnya variasi campuran abu ampas tebu.

\subsection{Saran}

Adapun saran pada penelitian ini adalah Diharapkan dapat dilakukan penelitian lanjutan dengan campuran Abu batubara (Fly ash) dengan variasi lama rendaman (perawatan).

\section{DAFTAR PUSTAKA}

Annual Book of ASTM Standard, Volume 04.02, Concrete and Agregates, 1997

....................., Standar Nasional Indonesia SNI 03-2847-2002 "Tata Cara Perhitungan Struktur Beton untuk Bangunan Gedung.

Asrullah, 2001, Kajian Pemanfaatan Limbah Elektroplating Sebagai Pengganti PC dan Pasir Dalam Mortar dan Pengembangan Uji Pelindian Melalui Multipel TCLP, Tesis Magister, ITB

Hanafi, A.S dan Nandang, A.R., Studi Pengaruh Bentuk Silika Dari Abu Ampas Tebu Terhadap Kekuatan Produk Keramik. Jurnal Kimia Indonesia, Vol. 5 (1), 2010, h.35-38

Haryono, S dan Primantari, L., Pemanfaatan Limbah Abu Ampas Tebu (Baggase Ash) Sebagai Bahan Substitusi Semen Untuk Meningkatkan Kuat Tekan dan Durabilitas Beton Pada Lingkungan Agresif. Majalah Ilmiah Kopertis Wilayah IV, Vol. XV No. 23 Th. 2005: 43-53

Nugraha P., Antoni, Teknologi Beton, Andi offset, yogyakarta, 2007 